\title{
Sistem Informasi Keuangan Berbasis Web Pada PT PLN UP3 Kotamobagu
}

\author{
Ester Toar ${ }^{1}$, Isni Maris Ayu Nintias², Christania Bawole ${ }^{3}$ \\ 1,2 Jurusan Teknik Informatika UNIMA; 3 Program Studi Teknik Informatika UNIMA \\ Emai; estertoar21@gmail.com
}

\begin{abstract}
Pt. PLN (Persero) UP3 Kotamobagu is one of the Customer Service Units under suluttenggo regional parent, as one of the State-Owned Enterprises (SOEs) which aims to generate revenue derived from marketing, electricity sales and operational services. In order to increase the marketing and sale of electricity to the company, then create an information system that is a financial information system. The Research Method used in this study is the Prototype method. Stages are: Needs Analysis,

Prototyping Building, Prototyping Evaluation, Coding Systems, Testing Systems, System Evaluation, and Using Systems
\end{abstract}

Keywords - Information System, Web, Prototype Method

\begin{abstract}
PT. PLN (Persero) UP3 Kotamobagu merupakan salah satu Unit Pelayanan Pelanggan yang dibawahi Induk Wilayah SULUTTENGGO, sebagai salah satu Badan Usaha Milik Negara (BUMN) yang bertujuan untuk memperoleh pendapatan yang berasal dari pemasaran, penjualan listrik dan jasa operasional. Untuk dapat meningkatkan pemasaran dan penjualan listrik pada perusahaan, maka di buat suatu sistem informasi yaitu sistem informasi keuangan. Metode Penelitian yang digunakan dalam penelitian ini adalah metode Prototype. Tahapan yang dilakukan yaitu : Analisis Kebutuhan, Membangun Prototyping, Evaluasi Prototyping, Mengkodekan Sistem, Menguji Sistem, Evaluasi Sistem, dan Menggunakan Sistem.
\end{abstract}

Kata Kunci-Sistem Informasi Keuangan, Web, Metode Prototype

\section{PENDAHULUAN}

Seiring dengan perkembangan kemajuan teknologi saat ini, masyarakat semakin menikmati kemajuan teknologi tersebut, seperti jaringan internet yang semakin mudah untuk diaplikasikan oleh masyarakat dalam kesehariannya. Kemajuan teknologi ini pun terjadi pada dunia perusahaan untuk lebih memudahkan proses kegiatan perusahaan yang berkaitan dengan sistem informasi keuangan di perusahaan.

Laporan keuangan suatu perusahaan merupakan salah satu bentuk informasi yang dapat disampaikan secara relevan apabila menggunakan sistem yang tepat pula, hal tersebut sangat bermanfaat bagi perusahaan, terutama bagi para pengambil keputusan sehingga dapat menentukan segala sesuatunya dengan efektif bagi kelangsungan hidup perusahaan.

Bagian Keuangan PT.PLN Persero pada pelaksanaan tugasnya masih dijalankan secara manual dalam perhitungan, pencatatan jurnal dan sebagian masih menggunakan Tools seperti Microsoft Office Excel. Pendataan keuangan yang dilakukan secara manual menyebabkan terjadinya kesalahan data dan membutuhkan waktu serta cara yang rumit.

Oleh karena itu dibutuhkan sistem informasi keuangan berbasis web agar dapat menunjang, mengatasi masalah serta memudahkan pihak bagian keuangan.

\section{TINJAUAN PUSTAKA}

\section{A. Sistem Informasi}

Sistem Informasi adalah sistem yang dibuat secara umum berdasarkan seperangkat komputer dan komponen manual yang dapat dikumpulkan, disimpan dan diolah untuk menyediakan output kepada user.

\section{B. Website}

Website adalah sebuah kumpulan halaman pada suatu domain di internet yang dibuat dengan tujuan tertentu dan saling berhubungan serta dapat diakses secara luas melalui halaman depan (home page) menggunakan sebuah browser menggunakan URL website. 


\section{Basis Data}

Basis Data adalah kumpulan informasi yang disimpan di dalam komputer secara sistematik sehingga dapat diperiksa menggunakan suatu program komputer untuk memperoleh informasi dari basis data tersebut. Basis Data adalah representasi kumpulan fakta yang saling berhubungan disimpan secara bersama sedemikian rupa dan tanpa pengulangan (redudansi) yang tidak perlu, untuk memenuhi berbagai kebutuhan.

\section{Keuangan}

Keuangan (bahasa Inggris: finance) mempelajari bagaimana cara mengetahui berbisnis individu, meningkatkan organisasi, mengalokasi, menggunakan sumber daya moneter dengan sejalannya waktu, dan juga menghitung risiko dalam menjalankan proyeknya.

\section{METODE PENGEMBANGAN SISTEM}

Pada penelitian ini, kami menggunakan metode pengembangan prototype. Metode prototype sendiri merupakan sebuahmetode yang menggambarkan siklus hidup sebuah sistem yang bertujuan memberikan gambaran sistem yang akan dibangun kepada pelanggan berdasarkan pada antarmuka dan konsep logika. [11]. Berikut adalah tahapan metode pengembangan prototype:

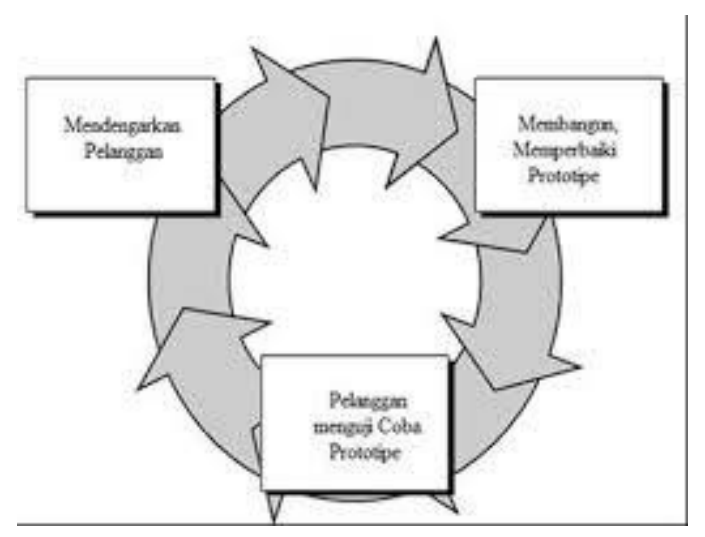

Gbr. 1. Prototype digilib uisdg 2014

\section{HASIL DAN PEMBAHASAN}

\section{A. Mendengarkan Pelanggan}

Dari hasil mendengarkan dan menganalisis kebutuhan yang dilakukan dengan Kepala bagian keuangan dalam hal ini adalah sebagai berikut:

1) Halaman login untuk Manager Keuangan

2) CRUD data keuangan oleh Manager Keuangan

3) CRUD data karyawan oleh Karyawan

4) Penginputan data Keuangan oleh Manager Keuangan

5) Penginputan data karyawan oleh karyawan

6) Cetak Laporan Data Keuangan oleh Manager Keuangan

7) Cetak Laporan Data Karyawan oleh Karyawan

\section{B. MEMBANGUN/MEMPERBAIKI PROTOTYPE}

1) Perancangan Sistem

a. Use case Diagram

Use case atau diagram use case merupakan pemodelan untuk melakukan sistem informasi yang akan dibuat.

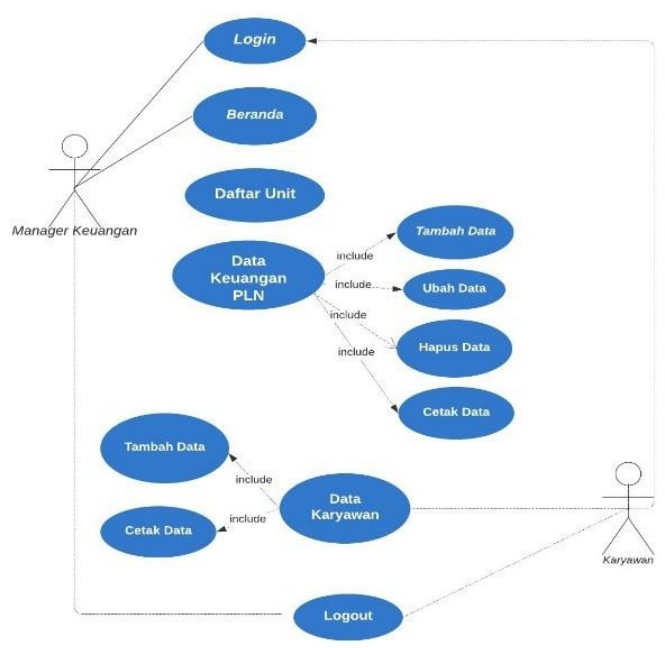

Gbr. 2. Use Case Diagram

Pada gambar use case diatas, Manager Keuangan adalah pengguna yang berinteraksi dengan system dalam hal ini yaitu login, beranda, daftar unit, data keuangan, serta logout. Sedangkan Karyawan adalah pengguna yang berinteraksi dengan system dalam hal ini yaitu Input data karyawan dan logout.

b. Activity Diagram

Activity diagram atau diagram aktivitas menggambarkan aliran kerja dari sebuah sistem. Berikut adalah activity diagram dari Sistem Informasi Keuangan PT PLN UP3 Kotamobagu; 


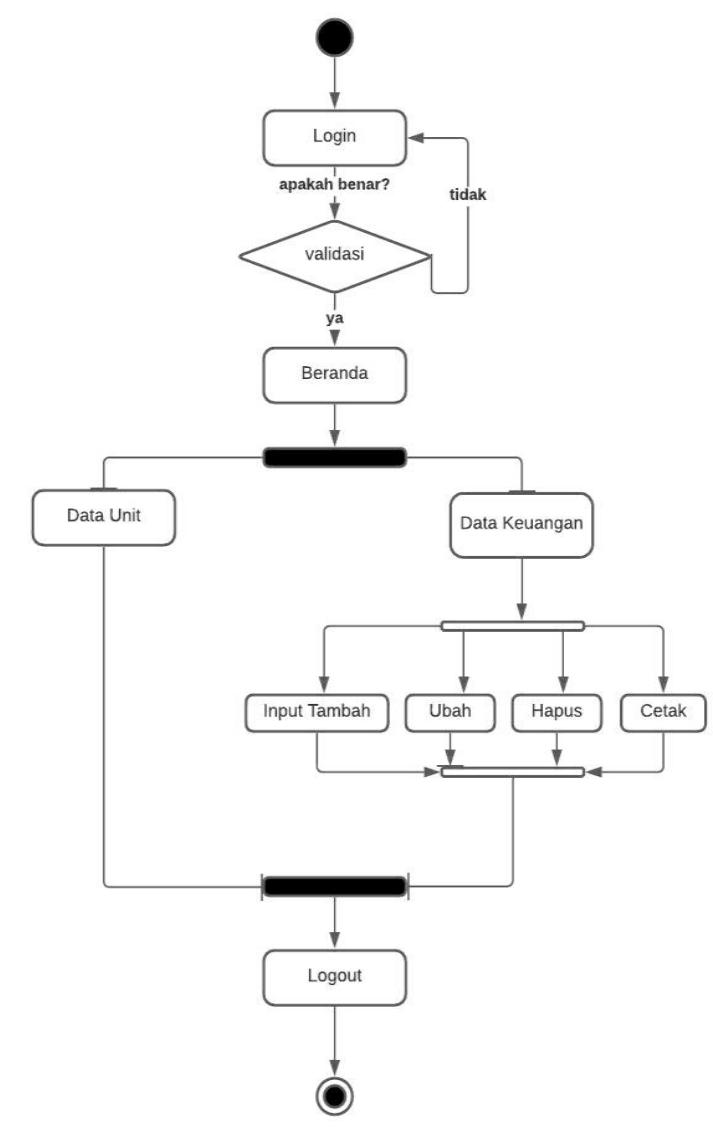

Gbr. 3. Activity Diagram Sistem Informasi Keuangan oleh Manager Keuangan

Pada gambar Activity Diagram diatas menunjukkan bagaimana aliran kerja dari Sistem Informasi Keuangan oleh manager keuangan.Untuk dapat menjalankan sistem ini, pertama-tama manager keuangan harus memulai dengan cara melakukan login. Kemudian sistem melakukan validasi username dan password jika berhasil, sistem akan menampilkan menu beranda, dan jika tidak berhasil maka manager keuangan harus memasukan Kembali username dan password. Setelah manager keuangan masuk ke dalam sistem, manager keuangan akan mengecek info-info dalam daftar unit kemudian akan beralih ke menu data keuangan untuk melakukan pengimputan data keuangan, mengubah data keuangan, menghapus serta dapat mencetak data keuangan. Jika sudah selesai maka manager keuangan akan melakukan logout agar dapat keluar dari website tersebut.

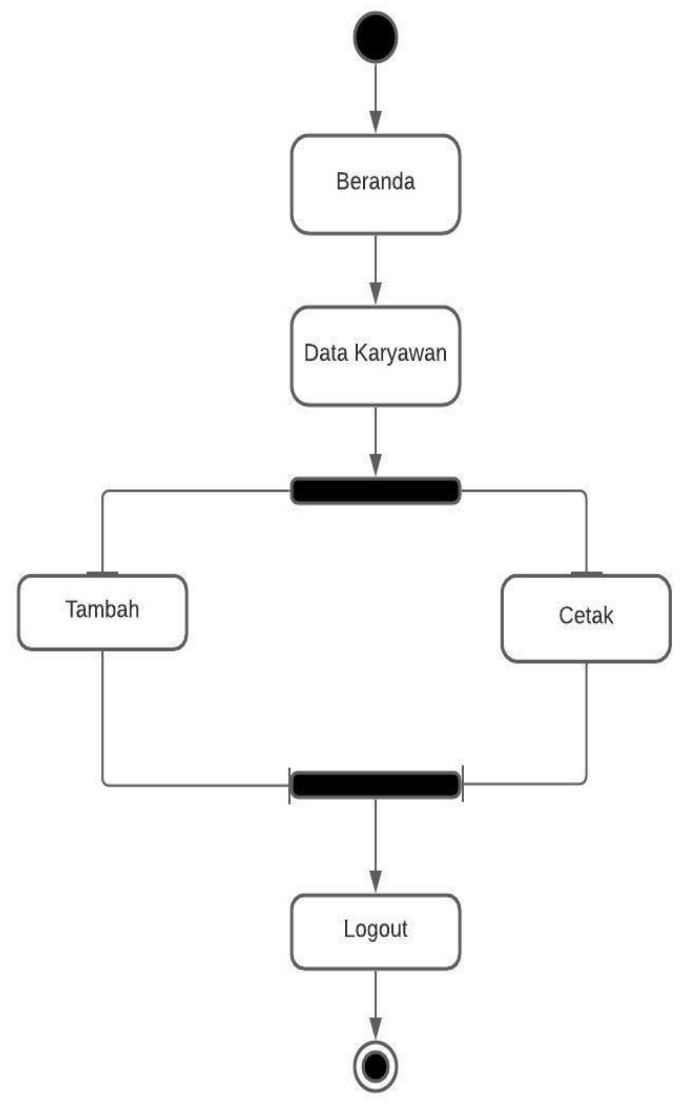

Gbr. 4. Activity Diagram Input Data Karyawwan

Pada gambar Activity Diagram diatas menunjukkan bagaimana aliran kerja dari Input Data Karyawan oleh seorang karyawan.Untuk dapat menjalankan sistem ini, pertama-tama karyawan harus bisa masuk ke dalam menu beranda kemudian diarahkan untuk memilih menu data karyawan, setelah masuk pada menu data karyawan maka seorang karyawan akan melakukan penginputan, pengubahan, serta penghapusan data karyawan. Selain itu juga diaraahkan untuk mencetak data yang telah diinput. Setelah selesai maka Karyawan akan melakukan logout agar dapat keluar dari website tersebut.

\section{c. Sequence Diagram}

Sequence diagram menggambarkan kelakuan objek pada use case dengan mendeskripsikan waktu hidup objek dan message yang akan dikirimkan dan diterima antar objek. 


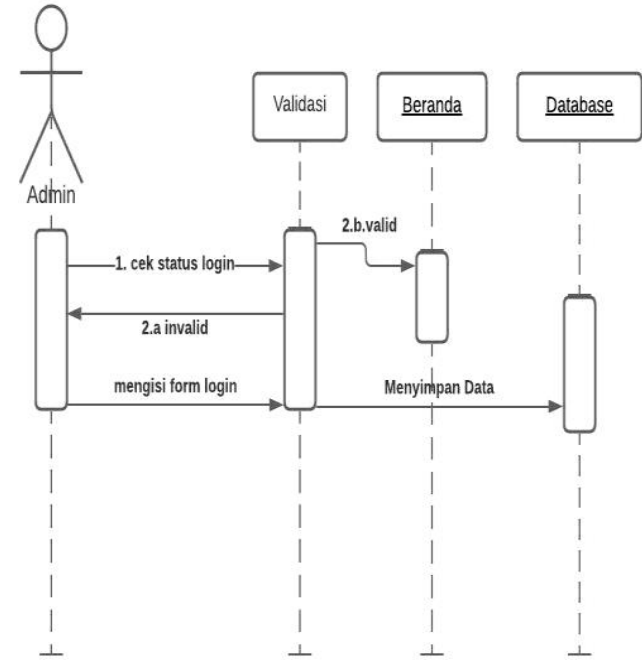

Gbr. 5. Sequence Diagram Login Admin

Pada gambar sequence diagram diatas menggambarkan proses Login Admin dalam Sistem Informasi Keuangan PT PLN UP3 Kotamobagu. user melakukan validasi cek status login jika berhasil maka akan diarahkan ke menu beranda jika tidak maka akan kembali melakukan cek status login. User akan melakukan pengisian form data login dan kemudian form data tersebut akan disimpan ke dalam database.

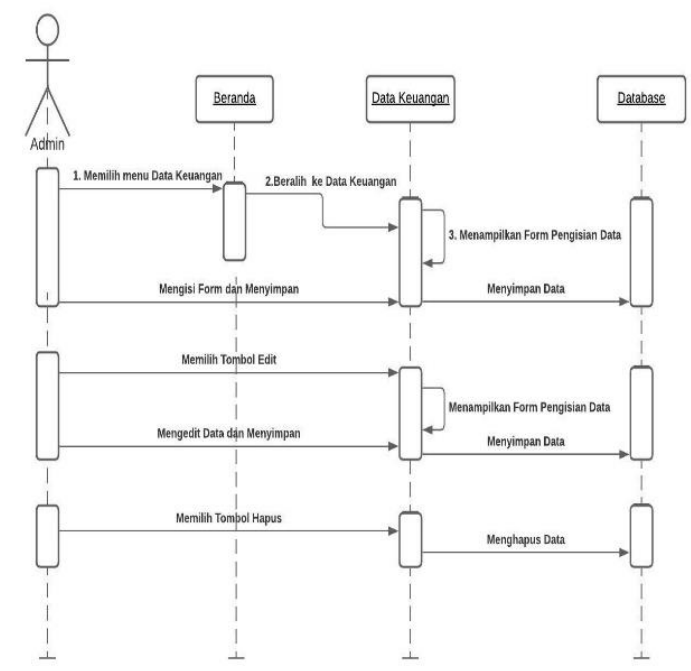

Gbr. 6. Sequence Diagram Pengelolahan Data Keuangan

Pada gambar sequence diagram diatas menggambarkan proses pengelolaan data keuangan dalam Sistem Informasi Keuangan PT PLN UP3 Kotamobagu. Manager keuangan memilih menu data keuangan dalam tampilan beranda kemudian akan diarahkan ke dalam menu data keuangan dan system akan menampilkan form pengisian data input keuangan dan mengisi form input data keuangan kemudian menyimpannya ke dalam database. Manager Keuangan juga dapat melakukan perubahan serta penghapusan data keuangan pada menu data keuangan kemudian menyimpannya ke dalam database.

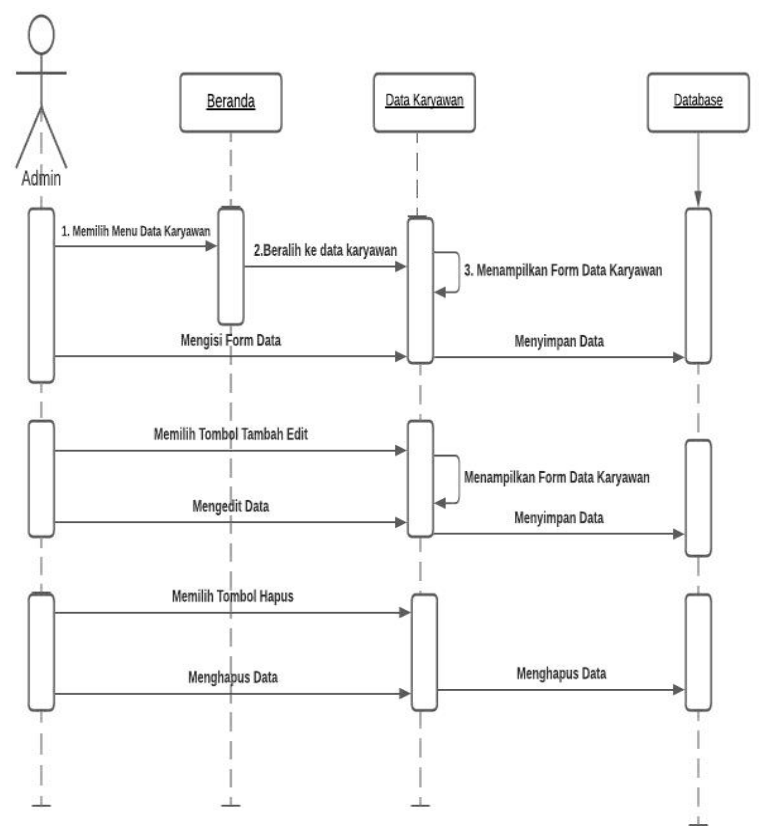

Gbr. 7. Sequence Diagram Pengelolaan Data Karyawan

Pada gambar sequence diagram diatas menggambarkan proses pengelolaan data karyawan dalam Sistem Informasi Keuangan PT PLN UP3 Kotamobagu. Karyawan memilih menu data karyawan dalam tampilan beranda kemudian akan diarahkan ke dalam menu data karyawan dan system akan menampilkan form pengisian data input karyawan dan mengisi form input data karyawan kemudian menyimpannya ke dalam database. Karyawan juga dapat melakukan perubahan serta penghapusan data karyawan pada menu data karyawan kemudian menyimpannya ke dalam database. 


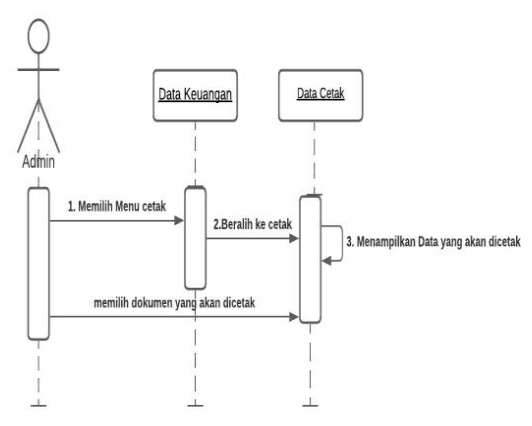

Gbr. 8. Sequence Diagram Cetak Data Keuangan

Pada gambar sequence diagram diatas menggambarkan proses pencetakkan data keuangan dalam Sistem Informasi Keuangan PT PLN UP3 Kotamobagu. Manager Keuangan memilih menu cetak dalam tampilan data keuangan kemudian akan diarahkan ke tombol cetak data dan system akan menampilkan data yang akan dicetak.

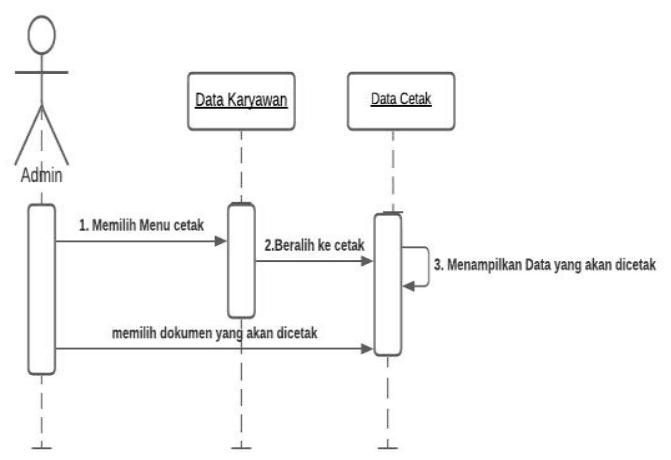

Gbr. 9. Sequence Diagram Cetak Data Karyawan

Pada gambar sequence diagram diatas menggambarkan proses pencetakkan data karyawan dalam Sistem Informasi Keuangan PT PLN UP3 Kotamobagu. Karyawan memilih menu cetak dalam tampilan data karyawan kemudian akan diarahkan ke tombol cetak data dan system akan menampilkan data karyawan yang akan dicetak.

\section{d. Class Diagram}

Diagram kelas atau class diagram menggambarkan struktur sistem dari segi pendefinisan kelas-kelas yang akan dibuat untuk membangun sistem.

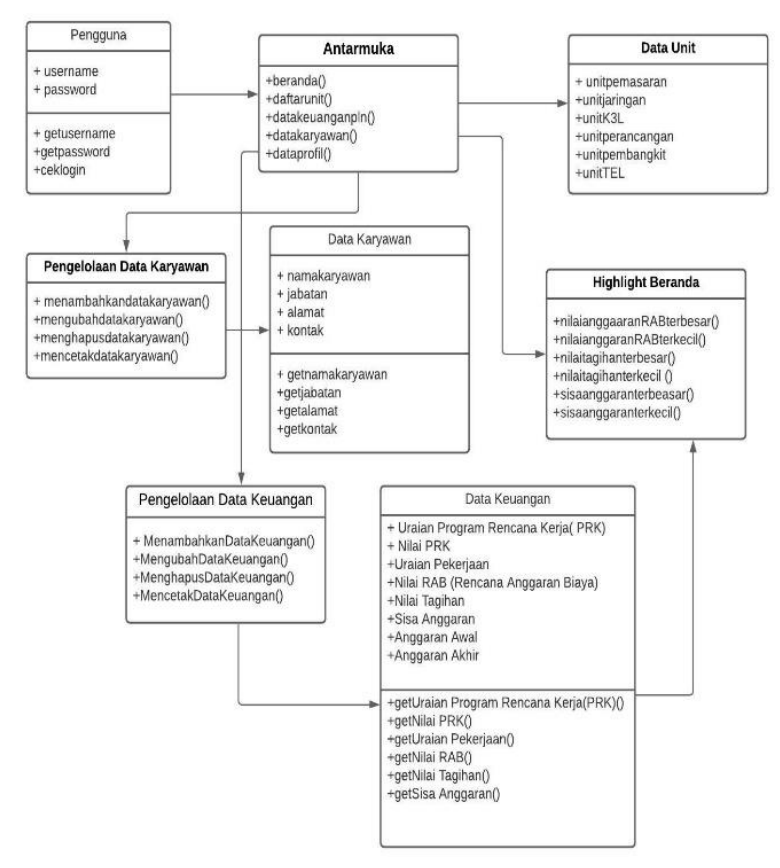

Gbr. 10. Class Diagram

Pada gambar Class Diagram menggambarkan tabeltabel, atribut dan fungsi dari sistem yang dikembangkan dan juga hubungan antara tabel- tabel. Disini terdapat 8 tabel yaitu tabel pengguna ,tabel antarmuka, tabel Data Keuangan, tabel pengelolaan data keuangn, tabel karyawan, tabel pengelolaan data karyawan, tabel unit, dan tabel highlight beranda,

2) Pengkodean

Pengembang menggunakan PHP MySQL Untuk database. Juga menggunakan xampp versi 3.2, menggunakan Notepadd sebagai editor pengolah codingnya. Penulis menggunakan firefox sebagai Web Browser. 


\section{3) PROTOTIPE}

Berikut ini adalah beberapa tampilan prototype :

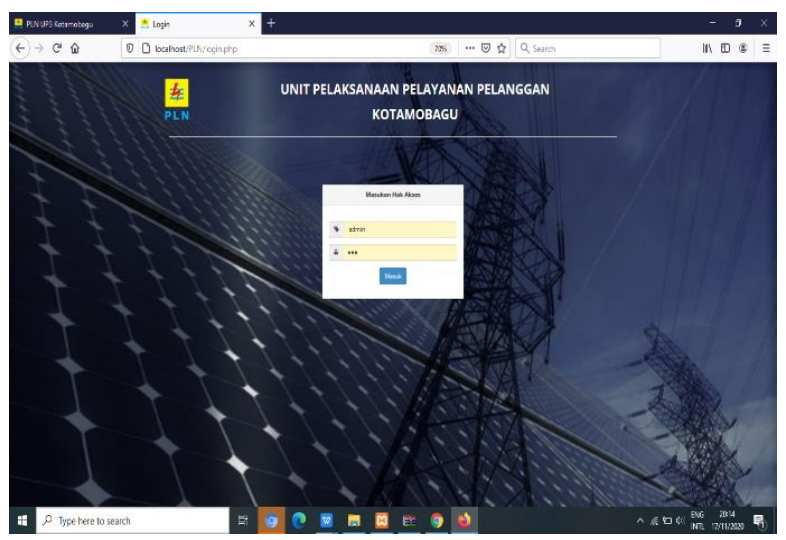

Gbr.11. Halaman Login Sistem

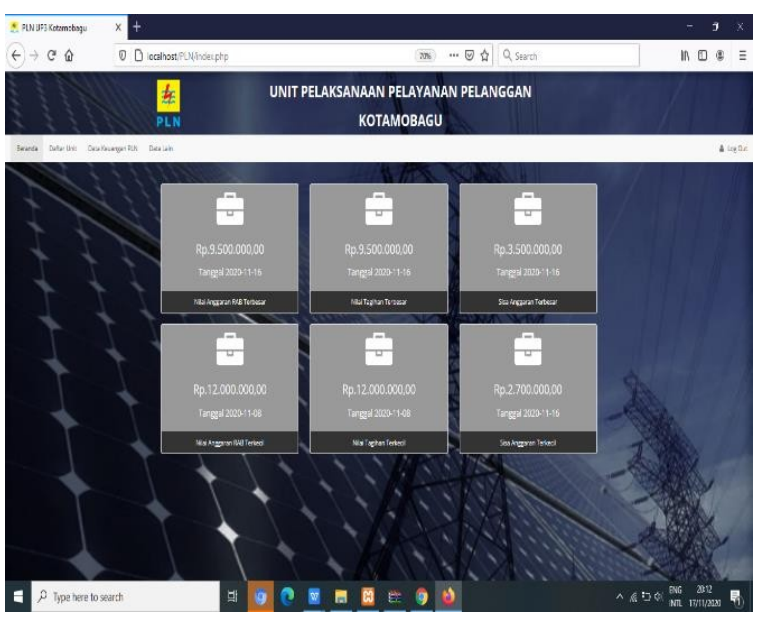

Gbr.12. Halaman Beranda

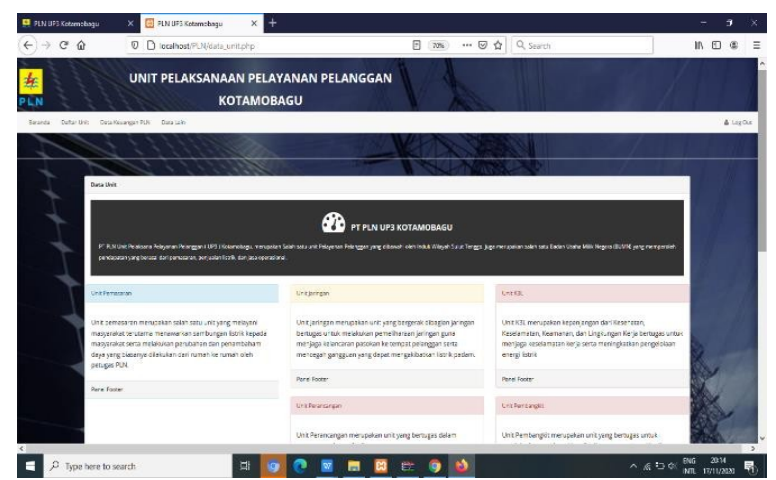

Gbr.13. Halaman Daftar

Unit

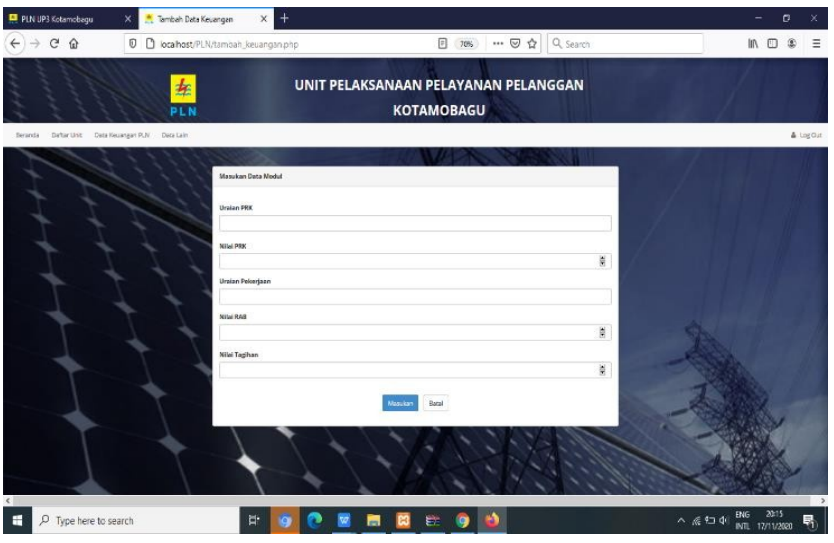

Gbr.14. Halaman Form Pengelolaan Data Keuangan

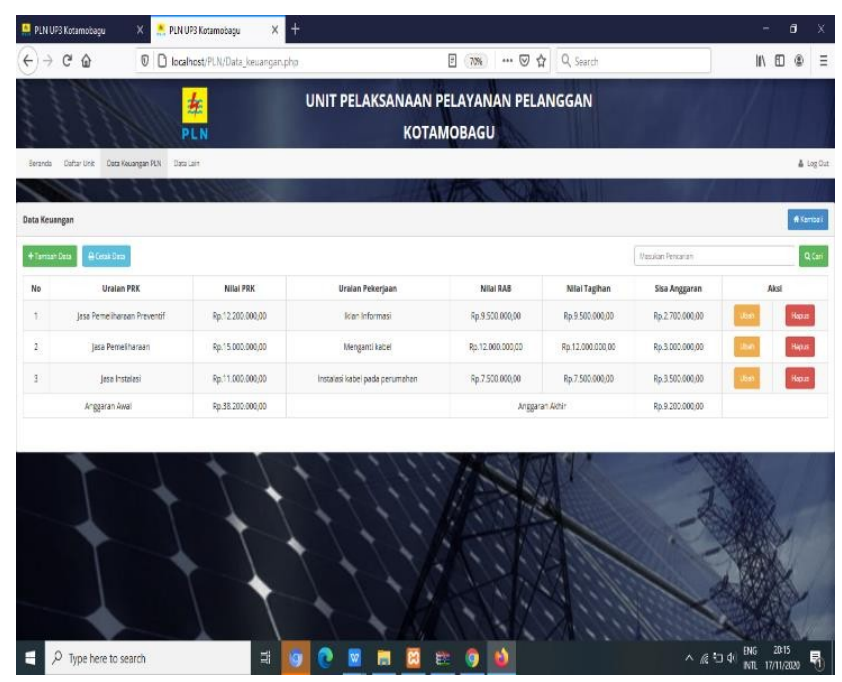

Gbr.15. Halaman Tampilan Data Keuangan

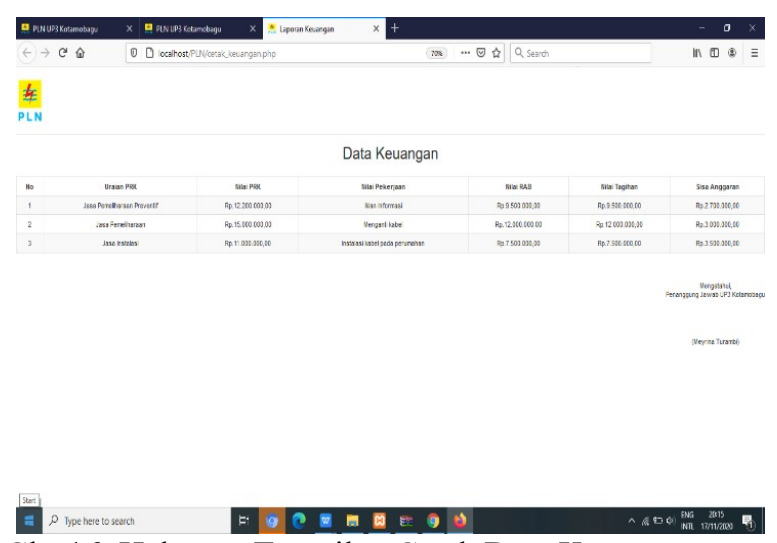

Gbr.16. Halaman Tampilan Cetak Data Keuangan 


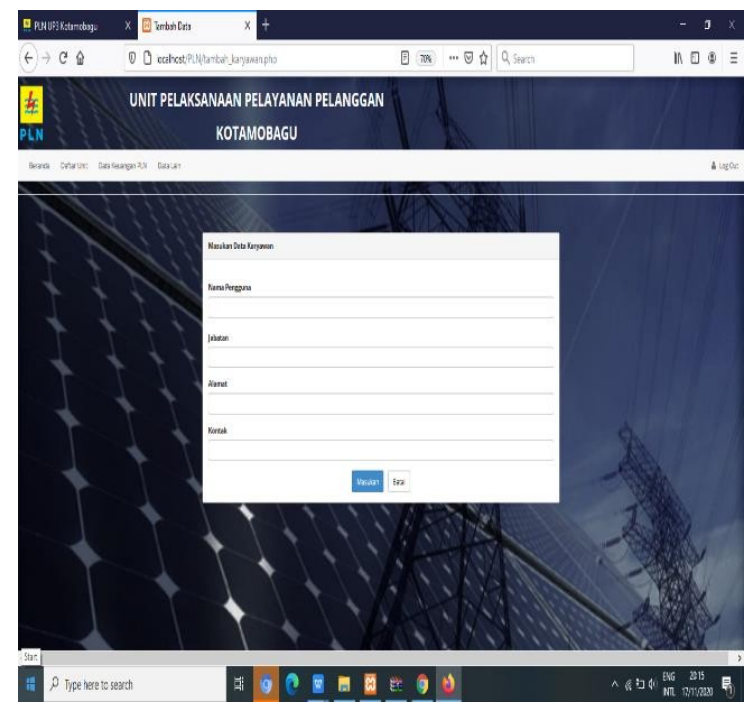

Gbr.17. Halaman Tampilan Form Pengelolaan Data Karyawan

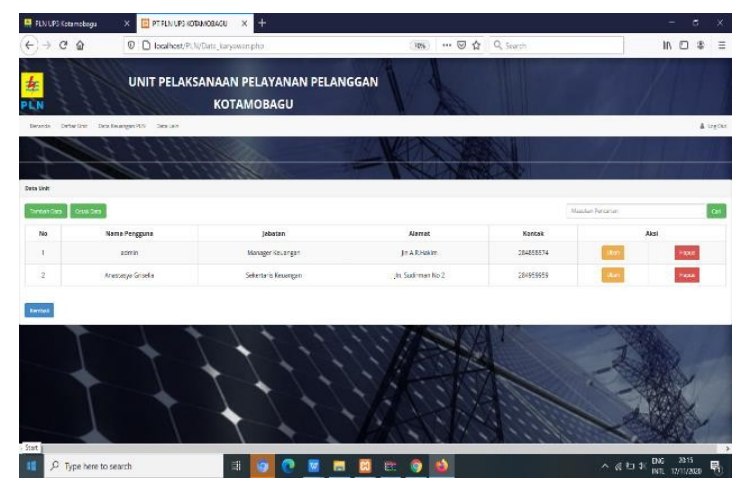

Gbr.18. Halaman Tampilan Data Karyawan

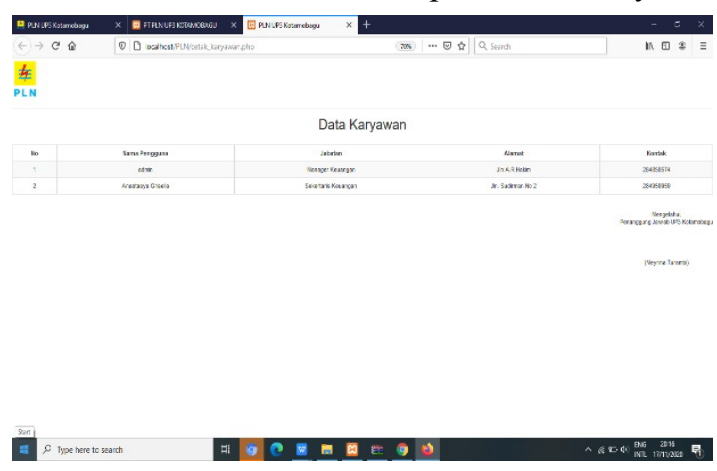

Gbr.19. Halaman Tampilan Cetak Data

\section{Karyawan}

\section{KESIMPULAN}

Dengan selesainya pelaksanaan kerja praktek di PT PLN UP3 KOTAMOBAGU, kami telah membuat aplikasi " Sistem Informasi Keuangan Berbasis Web" yang dapat membantu Bagian Keuangan PT.PLN Persero pada pelaksanaan tugasnya karena sebagian dilakukan secara manual dalam perhitungan, pencatatan jurnal dan sebagian menggunakan Tools seperti Microsoft Office Excel. Pendataan keuangan yang dilakukan secara manual menyebabkan terjadinya kesalahan data dan membutuhkan waktu serta cara yang rumit. Oleh sebab itu terkadang pendataan tidak maksimal, sehingga acuan terhadap efektifitas kinerja baik dalam perhitungan keuangan maupun dalam pencatatan data keuangan belum akurat. Dengan adanya aplikasi ini diharapkan mampu mengatasi masalah serta memudahkan pihak bagian keuangan.

\section{DAFTAR PUSTAKA}

[1] P. Kanani and M. Padole, "Deep learning to detect skin cancer using google colab," Int. J. Eng. Adv. Technol., 2019, doi: 10.35940/ijeat.F8587.088619.

[2] R. Zaman Khan, "Hand Gesture Recognition: A Literature Review," Int. J. Artif. Intell. Appl., 2012, doi: 10.5121/ijaia.2012.3412.

[3] Y. Lecun, Y. Bengio, and G. Hinton, "Deep learning," Nature. 2015, doi: 10.1038/nature14539.

[4] Sumit Saha, "A comprehensive guide to convolutional neural networks," Medium, 2018.

[5] E. Supriyati and M. Iqbal, "Recognition System of Indonesia Sign Language based on Sensor and Artificial Neural Network," MAKARA J. Technol. Ser., 2013, doi: 10.7454/mst.v17i1.1924.

[6] M. M. Zaki and S. I. Shaheen, "Sign language recognition using a combination of new vision based features," Pattern Recognit. Lett., 2011, doi: 10.1016/j.patrec.2010.11.013.

[7] A. Krizhevsky, I. Sutskever, and G. E. Hinton, "ImageNet classification with deep convolutional neural networks," Commun. ACM, 2017, doi: $10.1145 / 3065386$.

[8] V. P. Rantung, O. Kembuan, P. T. D. Rompas, A. Mewengkang, O. E. S. Liando, and J. Sumayku, "InMemory Business Intelligence: Concepts and Performance," in IOP Conference Series: Materials Science and Engineering, 2018, vol. 306, no. 1, doi: $10.1088 / 1757-899 X / 306 / 1 / 012129$. 